\title{
Colon Carcinoma Metastatic in the Lung
}

National Cancer Institute

\section{Source}

National Cancer Institute. Colon Carcinoma Metastatic in the Lung. NCI Thesaurus. Code C89815.

A carcinoma that originates from the colonic wall and has spread to the lungs. 